\section{Homenaje a los maestros Cora Mayers y Alfredo Demaría}

\author{
CARLOS G. OSORIO
}

\section{Tribute to the teachers Cora Mayers Glehy and Alfredo Demaría Andreani}

Dr. Cora Mayers Glehy, was the director of the Nursing School, head of the Department of Health Education of the General Health Office, a founding member of the Pediatric Society and Dr. Alfredo Demaría Andreani, was a prominent student leader, first sanitarian graduated in the University of John Hopkins, director of Health, professor of the Chair of Hygiene and Preventive Medicine. Both were brilliant academics of the Faculty of Medicine of the University of Chile in the early 1930's and great achievements were expected from them by the medical and university community. These hopes and longings were destroyed when they tragically ended their lives on the morning of a Monday, January 12, 1931.

(Rev Med Chile 2017; 145: 1179-1183)

Key words: Chile; Health Education; History of Medicine; History of Nursing; Public Health.

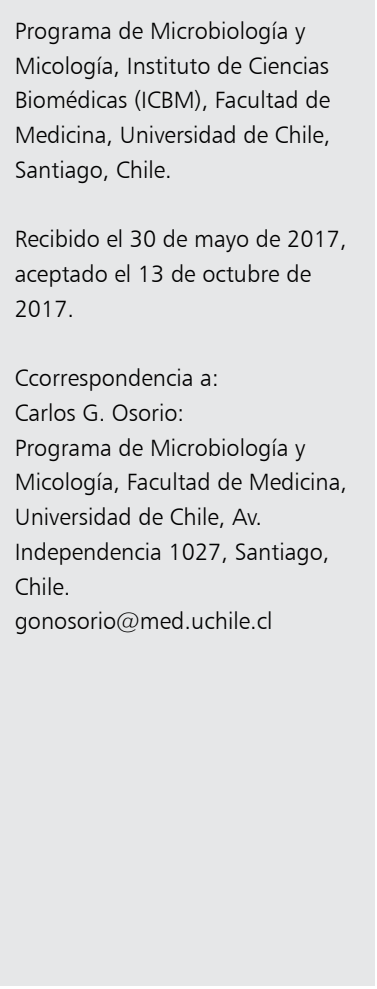

\section{La Facultad de Medicina en 1930}

I

a Facultad de Medicina, la Universidad de Chile y el país vivían entonces momentos de crisis. En la primera mitad de la década de 1920 en Chile se vivió una sensación de gran prosperidad económica, estimulada por un fuerte aumento del gasto público y endeudamiento externo. Esta prosperidad tuvo un fin abrupto cuando se desató la gran crisis económica internacional de 1929. La agitación estudiantil junto a la crisis financiera terminó finalmente por derribar al gobierno del presidente Carlos Ibáñez del Campo quien partió al exilio el 26 julio de $1931^{1}$.

\section{La Dra. Cora Mayers Glehy}

La Dra. Mayers nació en Valparaíso en 1895 (según registro de defunción del Cementerio General, 1931). Tempranamente demostró su preclara inteligencia cursando sus estudios escolares con singular brillo para titularse de bachiller a sus
15 años. Ingresó luego a la Facultad de Medicina donde se recibió de Médico Cirujano el 17 de noviembre de 1917 cuando tan sólo tenía 22 años². Su tesis para optar al grado de licenciado, publicada en 1917, se tituló: Algunas consideraciones sobre puericultura antenatal (Tesis de licenciatura, 1917, Museo Historia de la Medicina, Universidad de Chile). En el prefacio de esta obra podemos leer lo siguiente: "No hay ni puede haber nada más interesante para un país, que lo que se relaciona con su población, esto es, con su vitalidad, pues la verdadera fuerza de una nación, descansa en la homogeneidad de su raza y en el número de sus habitantes." Prosigue más adelante con lo siguiente: "En ningún país del mundo, la infancia desaparece como en el nuestro, barrida por una racha de muerte que deja desolados y desiertos los hogares. A pesar de la fecundidad de la mujer chilena y de lo envidiable de nuestro clima, nuestra población no aumenta debido a que casi la tercera parte de los niños que nacen, encuentran junto a su cuna la sepultura que devora sus existencias en flor". Luego introduce el tema específico de 


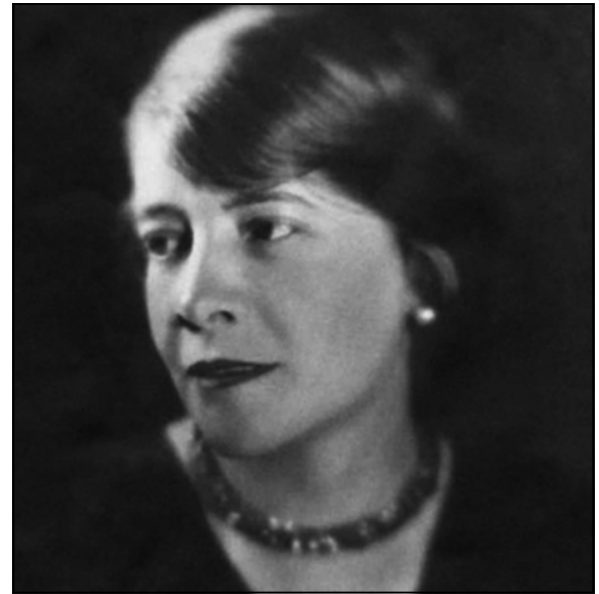

Figura 1. Dra. Cora Mayers Glehy (1895-1931). Fuente: Museo Historia de la Medicina, Facultad de Medicina, Universidad de Chile.

su memoria: "Si se toma en cuenta que la obra de la muerte, no es sólo un trabajo de selección que concluye con los débiles para dejar a los fuertes, sino que es el golpe ciego de la tuberculosis, el alcohol, las enfermedades venéreas, etc., que se descargan sobre la madre misma, sin reparar sobre el valioso tesoro que guarda en sus entrañas...". Hoy, en una mirada retrospectiva, conmueve leer estas palabras, que muestran claramente el certero diagnóstico que la autora tenía sobre el drama que nuestra nación vivía en esa época respecto de la mortalidad infantil. Además el texto permite formarnos una idea clara sobre su aguda inteligencia y personalidad. Posteriormente recibió una beca del gobierno de Chile para estudiar Pediatría en la Sorbonne de París. También realizó estudios de la especialidad en Londres y en el hospital Emperatriz Victoria de Berlín. Luego de su regreso al país participó en innumerables actividades, tales como: creación del Servicio de Puericultura en el Hospital San Borja, delegada de Chile en el Congreso Panamericano del Niño (1924), socia fundadora de la Sociedad Pediátrica, jefa del Departamento de Educación Sanitaria de la Dirección General de Sanidad (1925), entre otras. Su carrera académica se inició con la fundación de la Escuela de Enfermeras Sanitarias en 1926, la cual inició sus actividades en 1927. En 1929 dicha Escuela fue absorbida por la Escuela de Enfermeras del Estado. Posteriormente, en reconocimiento de sus méri- tos, la Universidad de Chile le permitió crear en la Escuela de Medicina, en el antiguo pensionado de la sección mujeres del Hospital San Vicente de Paul (actual Departamento de Educación en Ciencias de la Salud o DECSA), la nueva Escuela de Enfermería de la Universidad de Chile, siendo nominada como su segunda Directora en $1930^{3}$. Entre sus principales obras podemos citar: La mujer defensora de la raza (1925) y la puericultura al alcance de todos (obra póstuma de 1933) ${ }^{2}$ (Figura 1).

\section{El Dr. Alfredo Demaría Andreani}

El Dr. Alfredo Demaría nació en Valparaíso en 1898 (Registro de nacimiento, Valparaíso, 1898). Durante sus estudios de Medicina en la Universidad de Chile, se destacó como uno de los dirigentes con mayor capacidad intelectual, siendo presidente del Centro de Alumnos de Medicina en 1919 cuando el presidente era Juan Gandulfo. En ese período, la organización sufrió una de las olas represivas más violentas de su historia. Entre julio y octubre de 1920 los dirigentes de la Federación fueron perseguidos por su cercanía al anarquismo y su trabajo social con los sindicatos y organizaciones de trabajadores, ola conocida como el "proceso a los subversivos", que culminó con la muerte en la cárcel del estudiante y poeta José Domingo Gómez Rojas. El medio de difusión de los estudiantes era la revista Claridad, que tuvo entre sus redactores a Juan Gandulfo, Alfredo Demaría y Pablo Neruda, entre otros ${ }^{4}$. El Dr. Demaría obtuvo su grado de bachiller en Medicina en 1918 y de licenciado en Medicina en 1921 con su tesis titulada: Situación actual de la lucha contra las enfermedades venéreas (Tesis de licenciatura, 1922, Museo Historia de la Medicina, Universidad de Chile). En el prefacio de su tesis podemos leer lo siguiente: "Las enfermedades venéreas, o sea la sífilis, blenorrea y chancro blando, son las que presentan con mayor frecuencia entre todas las afecciones. Socialmente consideradas, son de una gravedad enorme, porque afectan la vitalidad de la raza y su profilaxis es difícil de realizar. Es casi imposible darse una cuenta exacta de la extensión y gravedad del problema, porque los enfermos ocultan su mal o no le dan la importancia que realmente tiene. En Chile el problema de las enfermedades venéreas está más agravado aún, por el alto porcentaje de afectados 


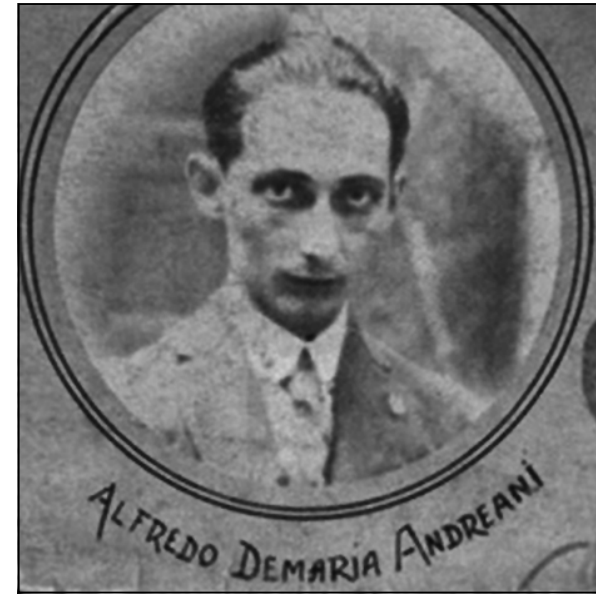

Figura 2. Dr. Alfredo Demaría Andreani (1899-1931). Fuente: Museo Historia de la Medicina, Facultad de Medicina, Universidad de Chile.

y por la intervención de otros factores como la incultura y el alcoholismo de la gran mayoría de la población.” Posteriormente a sus estudios de Medicina, el Dr. Demaría recibió el grado de doctor en Higiene Pública en la Universidad de Johns Hopkins, en los Estados Unidos, siendo el primer doctor sudamericano titulado en dicha disciplina y prestigiosa institución (Registro histórico de graduados, 1928, Universidad de Johns Hopkins). De vuelta en Chile se desempeñó profesionalmente como Director de Sanidad (1924) y luego como profesor titular del ramo de Higiene y Medicina Preventiva (1928) en la Facultad de Medicina de la Universidad de Chile ${ }^{5}$. El doctor Demaría sucedió en dicha Cátedra al Dr. Mamerto Cádiz, profesor de la Cátedra fusionada de Bacteriología e Higiene desde 1905, siendo por tanto el primer profesor de esta nueva, independiente y moderna Cátedra de Higiene y Medicina Preventiva ${ }^{3}$. Su sucesor en la Cátedra fue el afamado Dr. Lucio Córdova, quien en su clase inaugural con fecha de 15 abril de 1932 dijo sobre su inmediato antecesor: “. .. arrebatado desgraciadamente en los comienzos de la vida al progreso de nuestros servicios de Higiene y a la labor docente, que honraba con su brillante inteligencia y con su cuidada preparación científica. Su educación sanitaria la había adquirido en Estados Unidos de América, cuyos servicios de salubridad vigorosamente organizados y dotados de munificencia no sufrieron, como los de los países europeos, la acción disolvente de la lucha de cuatro años que consumió hombres y riqueza pública. Se adivina, a través de sus lecciones, esa precisión, ese cuidado de la exactitud, esa concordancia entre los detalles, que son las cualidades primordiales del organizador. Su enseñanza y el profesor mismo, respondía al momento en que se hacía oír, de mutaciones variadas, de reformas frecuentes de nuestras leyes sanitarias que buscaban la formula más conveniente para dar estabilidad, por algunos años, a los Servicios y al personal encargado de ellos"6 (Figura 2).

\section{La tragedia}

En la primera plana del Diario Ilustrado en su edición del día miércoles 14 de enero de 1931 se relatan los siguientes hechos: "En la mañana del lunes se encontraba la doctora señorita Mayers dedicada de lleno a sus actividades del cargo de directora de la Escuela de Enfermeras de la Universidad de Chile (en ese entonces su dirección era calle Panteón 1040; hoy el edificio pertenece al Departamento de Educación en Ciencias de la Salud DECSA). Había trabajado tesoneramente durante varias horas atendiendo las consultas correspondientes a su puesto y evacuando informes solicitados por la Dirección de Sanidad. La secretaria de la señorita Mayers dice que poco antes del medio día el Dr. Demaría hizo irrupción en la oficina. Ella salió del lugar y dejó a los protagonistas conversando sobre asuntos de carácter administrativo. Cinco minutos antes de las doce, cuando regresaba hacia la oficina de la Dra. Mayers, sintió dos detonaciones que le produjeron honda alarma. $\mathrm{Al}$ entrar encontró a la señorita Mayers muerta en el suelo. El Dr. Demaría profundamente pálido estaba parado a su lado... luego de huir del lugar de los hechos escuchó una tercera detonación que le produjo la certidumbre de la muerte del segundo protagonista..." (Diario ilustrado, 14 de enero de 1931, Biblioteca Nacional).

\section{Discurso fúnebre del Dr. Lucas Sierra}

"Educada por una madre ejemplar bajo la inexorable imposición de la pobreza y en los sanos principios de la moral cristiana que dignifican a la mujer, muere envuelta en la aureola de 
santidad que procura el cumplimiento integral de ellos.

Cora Mayers tuvo el privilegio de llegar al mundo con ese raro conjunto de cualidades físicas e intelectuales que permiten sobreponerse aún a los de más clara inteligencia; ahí radicaba el cariño, la conquista fácil que ella hiciera de toda persona que la trataba; dominaba y pasaba a ocupar lugar predilecto lo mismo entre sus camaradas que entre sus jefes o más altos mandatarios a que debió acercarse. Nutrida con la enseñanza de nuestra Escuela se empapó en el extranjero con el espíritu de sociabilidad y servicio a la colectividad que caracteriza a nuestros tiempos. Ese fue el vasto campo en que aquel corazón altruista en muy alto grado, orgullo del cuerpo médico de este país, experimentó la más grande satisfacción de su vida científica y de enseñanza. Servir a sus semejantes, enseñarles a vivir sanos y aptos para un trabajo consciente y duradero, he ahí su divisa. En esa colmena de entusiastas y abnegadas trabajadoras que ella supo cobijar en su escuela, regada con su propia sangre y las lágrimas del corazón de todas esas jóvenes, perdurará su recuerdo y el ejemplo de sus virtudes en la convicción profunda de que imitándolo se marcha en la senda del bien, de la prosperidad y gratitud de sus semejantes. Por ese camino trabajó con abnegación y voluntad inquebrantable por el engrandecimiento de su patria, porque estaba convencida de que la salud es la base de la riqueza y prosperidad de la nación. Los intelectuales de Chile ven desaparecer de su firmamento una de sus estrellas que, a semejanza de las otras, brillaba con luz propia, lo mismo dentro que fuera del país; pasarán seguramente muchas generaciones antes que puedan exhibir un ejemplar más bello de la mujer chilena. La vida de las rosas es corta..., sus perfumes puede el hombre conservarlos largo tiempo. Que las virtudes de la señorita doctora Cora Mayers sirvan a la mujer chilena de fuente de inspiración y engrandecimiento" (Diario ilustrado, 14 de enero de 1931, Biblioteca Nacional de Chile).

No hubo discurso para el Dr. Alfredo Demaría.

\section{Epílogo}

En una reciente visita al Cementerio General revisé los libros antiguos que registran los ingresos de cadáveres al recinto. El registro correspondiente a enero de 1931 contiene la siguiente información respecto de este caso: Cora Mayers, edad: 35 años, ciudad natal: Valparaíso, causa muerte: herida de bala; sepultura: Mausoleo Guillermo Labarca. En otra hoja aparece: Alfredo Demaría, edad: 32 años, ciudad natal: Valparaíso, causa de muerte: herida de bala, sepultura: nicho perpetuo 926 en muralla de la nueva sección oriente ladrillo. Puede extrañar el nombre del mausoleo donde fue sepultada la Dra. Cora Mayers, lo que amerita una breve explicación. Guillermo Labarca Hubertson fue un abogado y escritor chileno, casado con la educadora, escritora y destacada feminista Amanda Pinto Sepúlveda, que luego pasó a llamarse Amanda Labarca. Amanda Labarca era gran amiga de Cora Mayers, lo que probablemente explica el uso de su mausoleo familiar para dar descanso eterno a su querida amiga. Sin embargo, al revisar la lápida erigida sobre el Mausoleo de la familia Labarca no aparece el nombre de la Dra. Cora Mayers. Luego quise dirigirme al lugar de entierro del segundo protagonista. Al llegar al nicho 926 en la muralla de la nueva sección oriente sólo encontré un nicho derruido y sin nombre alguno.

"Dime: dónde están ahora todos aquellos señores y maestros que tú muy bien conociste cuando aún vivian y florecian en sus estudios? Otros, ahora, ocupan sus altos cargos y de ellos, tal vez, ni siquiera subsiste el recuerdo. Durante su vida parecían valer algo, pero ahora nadie habla de ellos. Cuan rápidamente pasa la gloria de este mundo!

Imitación de Cristo, Tomás de Kempis (1380-1471).

Dos jóvenes maestros brillantes de nuestra Facultad de Medicina vieron truncadas sus vidas en ese aciago día de enero de 1931. Los motivos de la tragedia se esfumaron junto a ellos y no hay razón para escarbar allí. Sin embargo, la brevedad de su brillante paso por la vida y el profundo olvido que los ha afectado desde entonces, debiera conmovernos e incentivarnos a recuperar su memoria así como la memoria de tantos otros que han sido ignorados por nuestra historia. Ellos contribuyeron a ser lo que hoy somos y ojalá las nuevas generaciones se entusiasmen en investigar nuestras raíces para entender mejor nuestro presente y poder así crear un mejor futuro. De todo tipo de hechos, incluso los más terribles, es posible extraer enseñanzas que sean capaces de iluminar y guiar nuestras vidas 


\section{Referencias}

1. Mellafe R, Rebolledo A, Cárdenas M. Historia de la Universidad de Chile. Santiago, Chile; Editorial Universidad de Chile: 1992. p. 145-162.

2. Tezanos S. Cora Mayers Gley. Bol. Hospital Viña del Mar 1991; 47: 196-203.

3. Sierra L. Cien años de la enseñanza de la medicina en Chile. An Fac Biol Méd 1934; 1: 1-134.
4. Moraga, F. La Federación de Estudiantes. Semillero de Líderes de la nación. 2005. Anales Universidad de Chile sexta Serie, No17, Santiago, Chile. Disponible en: http:// www.anales.uchile.cl/index.php/ANUC/article/viewArticle/870 [consultado el 10 mayo de 2017].

5. Anales de la Universidad de Chile y Boletín Consejo Universitario. Santiago, Chile; Editorial Universidad de Chile; 1928. p. 112.

6. Córdova L. El primer código sanitario de Chile. Rev Med Chile 1932; 60: 706-28. 